PREPARED FOR THE U.S. DEPARTMENT OF ENERGY, UNDER CONTRACT DE-AC02-76CH03073

PPPL-3957

PPPL-3957

UC-70

Solid State Neutral Particle Analyzer Array on NSTX

by

K. Shinohara, D.S. Darrow, A.L. Roquemore, S.S. Medley, and F.E. Cecil

May 2004

NM|

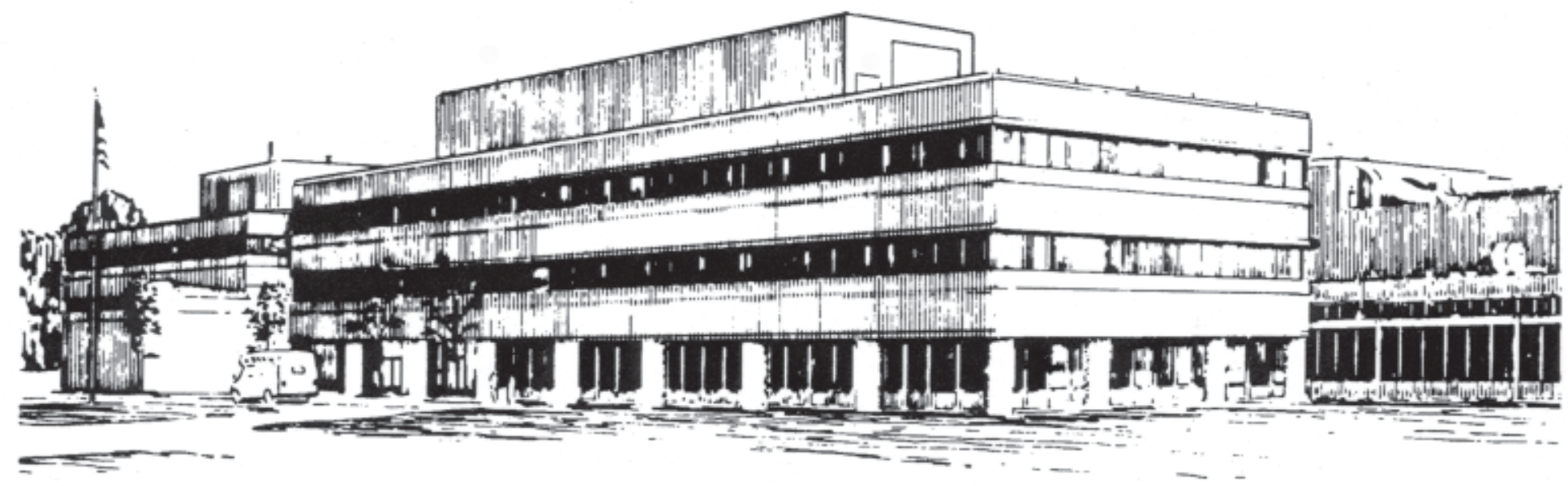

PRINCETON PLASMA PHYSICS LABORATORY PRINCETON UNIVERSITY, PRINCETON, NEW JERSEY 


\section{PPPL Reports Disclaimer}

This report was prepared as an account of work sponsored by an agency of the United States Government. Neither the United States Government nor any agency thereof, nor any of their employees, makes any warranty, express or implied, or assumes any legal liability or responsibility for the accuracy, completeness, or usefulness of any information, apparatus, product, or process disclosed, or represents that its use would not infringe privately owned rights. Reference herein to any specific commercial product, process, or service by trade name, trademark, manufacturer, or otherwise, does not necessarily constitute or imply its endorsement, recommendation, or favoring by the United States Government or any agency thereof. The views and opinions of authors expressed herein do not necessarily state or reflect those of the United States Government or any agency thereof.

\section{Availability}

This report is posted on the U.S. Department of Energy's Princeton Plasma Physics Laboratory Publications and Reports web site in Fiscal Year 2004. The home page for PPPL Reports and Publications is: http://www.pppl.gov/pub_report/

DOE and DOE Contractors can obtain copies of this report from:

U.S. Department of Energy

Office of Scientific and Technical Information

DOE Technical Information Services (DTIS)

P.O. Box 62

Oak Ridge, TN 37831

Telephone: (865) 576-8401

Fax: (865) 576-5728

Email: reports@adonis.osti.gov

This report is available to the general public from:

National Technical Information Service

U.S. Department of Commerce

5285 Port Royal Road

Springfield, VA 22161

Telephone: $1-800-553-6847$ or

(703) $605-6000$

Fax: (703) 321-8547

Internet: http://www.ntis.gov/ordering.htm 


\title{
Solid State Neutral Particle Analyzer Array on NSTX
}

\author{
K. Shinohara ${ }^{1}$, D. S. Darrow ${ }^{2}$, A.L. Roquemore ${ }^{2}$, S.S. Medley ${ }^{2}$, and F. E. Cecil ${ }^{3}$ \\ ${ }^{1}$ Japan Atomic Energy Research Institute Naka, Ibaraki, 311-0193, Japan \\ ${ }^{2}$ Princeton Plasma Physics Laboratory, Princeton, New Jersey, 08543, USA \\ ${ }^{3}$ Coloraodo School of Mines, Golden, Colorado 80401, USA
}

A Solid State Neutral Particle Analyzer (SSNPA) array has been installed on the National Spherical Torus Experiment (NSTX). The array consists of four chords viewing through a common vacuum flange. The tangency radii of the viewing chords are 60, 90, 100, and $120 \mathrm{~cm}$. They view across the three co-injection neutral beam lines (deuterium, $80 \mathrm{keV}$ (typ.) with tangency radii 48.7, 59.2, and $69.4 \mathrm{~cm}$ ) on NSTX and detect co-going energetic ions. A silicon photodiode used was calibrated by using a mono-energetic deuteron beam source. Deuterons with energy above $40 \mathrm{keV}$ can be detected with the present setup. The degradation of the performance was also investigated. Lead shots and epoxy are used for neutron shielding to reduce handling any hazardous heavy metal. This method also enables us to make an arbitrary shape to be fit into the complex flight tube.

\section{Introduction}

In a spherical tokamak, the magnetic moment is not always well conserved. The behavior of some ions cannot be adequately expressed with only the motion of the gyrocenter [1]. The interaction of these ions with mode activities or waves is of interest to plasma physics. There is also evidence of abnormal heating of bulk ions during neutral beam (NB) injection [2], which might relate to the peculiar behavior of energetic ions in a spherical tokamak. The enhanced transport of energetic ions due to Alfvén eigenmodes and other MHD activity is another interesting issue [3]. Thus it is important to measure the energetic ion behavior from many aspects. Neutral particle analysis (NPA) can measure the cross-sectionweighted line-integrated energy spectrum of the neutrals that emerge from the plasma. The measured neutrals are produced by the charge exchange between the ions and the neutrals of $\mathrm{D}^{0}$, or the hydrogen-like-carbon-ion, $\mathrm{C}^{5+}$. Through the cross-section-weighted line-integrated energy spectrum, we can deduce the energy distribution of energetic ions. Recently, we have installed the solid-state NPA (SSNPA) array with four sight lines on NSTX in order to measure the energy spectrum of energetic ions from different radial positions. Here, we 
introduce the characteristics of our system; the specification, the devices at the installation, calibration results, and the preliminary results on NSTX.

\section{Solid-state detector and its calibration}

Both a silicon diode detector and a natural diamond detector[4,[5] can be attached to the SMA connector as solid state detectors in our system. Although these detectors are sensitive to the energetic particles with energies up to several $\mathrm{MeV}$, our current interest is focused at energies less than $100 \mathrm{keV}$. Though the energy resolution of a solid state detector is worse than that of E//B spectrometer[6], it is easier to make a multi-channel system by virtue of the small size of the solid state detector.

There is a choice between the silicon diode detectors and the natural diamond. Here we are using a silicon diode detector (International Radiation Detectors inc, SXUVHS5 ) because of its higher carrier collection efficiency. The detector area has a square shape of $1 \mathrm{~mm} \times 1 \mathrm{~mm}$. The detector is operated at a bias voltage of $-15 \mathrm{~V}$ at room temperature. In order not to be affected by the visible radiation or low energy $\mathrm{x}$-ray from the plasma, a thin (150 $\mathrm{nm}$ ) Aluminum foil is placed in front of the detector as shown in Fig. 1. The stopping power due to this foil is estimated to be around $9 \mathrm{keV}$ for deuterons of energy between 40 and 120 $\mathrm{keV}$. At the front of the detector, there is a very thin layer of platinum silicide (a dead layer) whose thickness is $7 \mathrm{~nm}$. The energy loss from this layer is less than $1 \mathrm{keV}$.

An energy calibration was carried out using a mono-energetic source of deuterons from the low energy charged particle accelerator at the Colorado School of Mines. The output of the second stage amplifier was measured using a multi-channel analyzer (MCA). The MCA was calibrated using a pulser. The results are shown in Fig. 2(a) and (b). The peak position in the MCA waveform is plotted versus the beam energy in Fig. 2(a). There is good linearity in the range of 40 to $120 \mathrm{keV}$. It is found that the particles with energy larger than $40 \mathrm{keV}$ can be detected. The energy resolution (FWHM in the MCA waveform) is about 10 $\mathrm{keV}$, which is almost constant in the range of 40 to $120 \mathrm{keV}$. This lack of dependence on the energy suggests that electronic noise is dominant in the present setup. These calibration results were also consistent with calibration using an alpha source $\left({ }^{241} \mathrm{Am}\right)$ with energy of $5.49 \mathrm{MeV}$

We also carried out an investigation of the degradation characteristics of the detector. The detector was exposed to a relatively intense deuteron beam with an energy of $80 \mathrm{keV}$ for a total dose of about $2 \mathrm{E}+13$ deuterons $/ \mathrm{cm}^{2}$. The results are shown in Fig. 2(c). The efficiency 
almost linearly degrades. The value of $2.0 \mathrm{E}+13 \mathrm{dose} / \mathrm{cm}^{2}$ is roughly comparable to the exposure for one year of operation on NSTX Thus the detector can be degraded by about $50 \%$ in one year on NSTX. The energy calibration using NB injection into the vacuum vessel filled with a gas might be useful just before the precise experiment [7].

\section{Experimental setup}

The SSNPA array has been installed on NSTX. The array consists of four viewing chords through a common vacuum flange on NSTX. Figure 3 shows the viewing chords. The tangency radii of the viewing chords are $60 \mathrm{~cm}, 90,100 \mathrm{~cm}$, and $120 \mathrm{~cm}$. They view across the NB lines at co-going ions. The solid angle is 1.1E-4 sr with combination of collimating tube and aperture (Solid angle of collimating tube is 7E-4 sr). Thus the collimation is very sharp and the viewing chord can be regarded as a line. Furthermore, because of the small field-of-view, it is expected that the sensitivity to $\mathrm{x}$ ray, gamma ray and neutron emissions directly from plasma is small. The diameter of the circular aperture is 25 to $50 \mathrm{~L} / \mathrm{m}$. The aperture holder and $\mathrm{Al}$ foil holder covers the detector as shown in Fig. 1. It is also expected these holders work as an electromagnetic (EM) noise shield. Additionally, a copper foil covers each flight tube around a detector as another EM noise shield. Even though there are three EM noise shields, the detector picks up some noise and the noise determines the energy resolution. It is suspected the noise might come from a ground loop.

There are two flanges in one flight tube, and a long length of $\sim 3 \mathrm{~cm}$ between the detector and a feed-through. A small declination or obliquity of 3 degrees of these flange attachments prevents the aperture from aiming inside the sight line of collimating tube. Thus, careful installation of the detector and aperture structure is one of key points for this collimating structure.

Lead is one of most effective materials for gamma shielding. However, the process of the lead material is cost expensive because the lead is a hazardous heavy metal. Lead shots (tiny balls, $\sim 1.5 \mathrm{~mm}$ diameter) and epoxy is used to make "lead shield". One merit of this method is to facilitate making an arbitrary shape in situ. We can fit the shape of the lead shield to the complex flight tube very well. Thus the equivalent thickness to the "pure" lead is more than $3 \mathrm{~cm}$ at the thinnest part, though the density of the "lead shield" is about $58 \%$, compared with the "pure" lead. Another merit is the avoidance of unacceptable electromagnetic forces during disruptions, which could break the ceramic break and could lead to a vacuum leak. 
The lead shield is placed and fixed between the table and the lid of polyethylene, whose thickness is $50 \mathrm{~mm}$, and a G10 resin. The polyethylene block of $50 \mathrm{~mm}$ thickness and a several bags of polyethylene beads are also installed between the vacuum vessel and the lead shield. G10 is used as a support structure in order to avoid an unfavorable electromagnetic force.

Figure 4 shows the electronics diagram for the data acquisition. The shaping time of the second stage amplifier is determined so as to minimize noise and to have higher time resolution. Both of the integration and differentiation time are $500 \mathrm{~ns}$. The number of discriminators is eight. The separation of each discriminator becomes $12 \mathrm{keV}$ when the discriminator is set up with equally separated interval from 30 to $120 \mathrm{keV}$. The narrower separation and the narrower range of energy should be chosen, depending on the topic of a given experiment. The clock speed of the scaler is $1 \mathrm{kHz}$. The memory is enough for a onesecond discharge. Most of the electronics are installed in a rack, located about $5 \mathrm{~m}$ from the vacuum vessel.

A signal from one sight line is also fed into the MCA. The MCA has an enough resolution, however the result of the MCA is a time integration of one discharge. A PC which controlls the MCA is controlled manually from the control room.

\section{Results and future plan}

Figure 5 shows one of the preliminary results. NB (source B) is injected with the energy of $90 \mathrm{keV}$ starting at $0.1 \mathrm{~s}$. Particle fluxes increase strongly and decay rapidly to the steady level just after NB injections. This temporal behavior is not expected in TRANSP simulation, but this behavior is also observed in the E//B spectrometer. This is one of the interesting issues to be solved in future. Another large flux is also observed when the plasma is terminated. The temporal behavior of SSNPA is similar to that of E//B spectrometer. However, the preamps saturated at the occurrence of the large flux. The count rate is limited by the time response of the preamps. We need to reduce the aperture size to detect the large flux as a temporary measure, while the counts will get smaller during other periods.

The temporal evolution of the spectrum is shown in Fig. 6. The shoulder in the energy range of "-2" to "-4" is corresponds to the energy of the injected beam. This means the slowing down energy distribution is observed. On the other hand, several spiky large events are observed. Probably, these could originate from noise. We need to resolve these events or problems. 
Finally, we discuss the idea for the future improvement. The detector or the input of the preamplifier picks up EM noise. The noise determines the current energy resolution of 16 $\mathrm{keV}$. A reduction of noise by less than a half is preferable. The response of the preamps is relatively slow when the preamp is used with the current detector. The preamp is saturated when there is a large particle flux as mentioned above. This determines the maximum count rate at present. The fast preamp will provide the higher count rate. As mentioned also, the alignment of the collimating tube and the aperture is not easy. A custom-made feed-through may be useful.

\section{Acknowledgment}

The authors would like to acknowledge Mrs. T. Holoman,and L. Guttadora for the helpful technical assistance. This work was supported at PPPL by DOE Contract DE-AC02$76 \mathrm{CHO} 3073$.

\section{REFERENCE}

[1] R. J. Akers, et. al., Nucl. Fusion 42, 122 (2002)

[2] D. Gates, et. al. Phys. Rev. Lett. 87205003 (2001),

[3] E. D. Fredrickson, et. al., Phys. Plasma 10, 2852 (2003)

[4] A. V. Krasilnikov, et. al., J. Plasma Fusion Res. 75, 967 (1999)

[5] A. G. Alekseyv, et. al., Rev. Sci. Instrum. 74, 1905 (2003)

[6] S. S. Medley, et al. Rev. Sci. Instrum. 69, 2651 (1998), also S. S. Medley, ibid

[7] M. Osakabe et al., Rev. Sci. Instrum. 72, 788 (2001). 


\section{Figure caption}

Figure 1 Schematic view of collimating tube, aperture, $\mathrm{Al}$ foil and detector.

Figure 2 (a) Peak position of spectrum versus energy of beam source. One of spectra of MCA is also shown as an example in this panel(count vs channel), (b) FWHM of spectrum versus energy of beam source, (c) degradation of detector.

Figure 3 Viewing chords of SSNPA array are shown with the viewing chords of E//B spectrometer and injection lines of NB on NSTX.

Figure 4 Schematic diagram of electronics

Figure 5 Temporal evolution if Ip, NB power, counts in the scaler of sight-line \#1 of SSNPA, and in $\mathrm{E} / / \mathrm{B}$ spectrometer

Figure 6 Temporal evolution of energy spectrum of sight-line \#1 


\section{Figure}

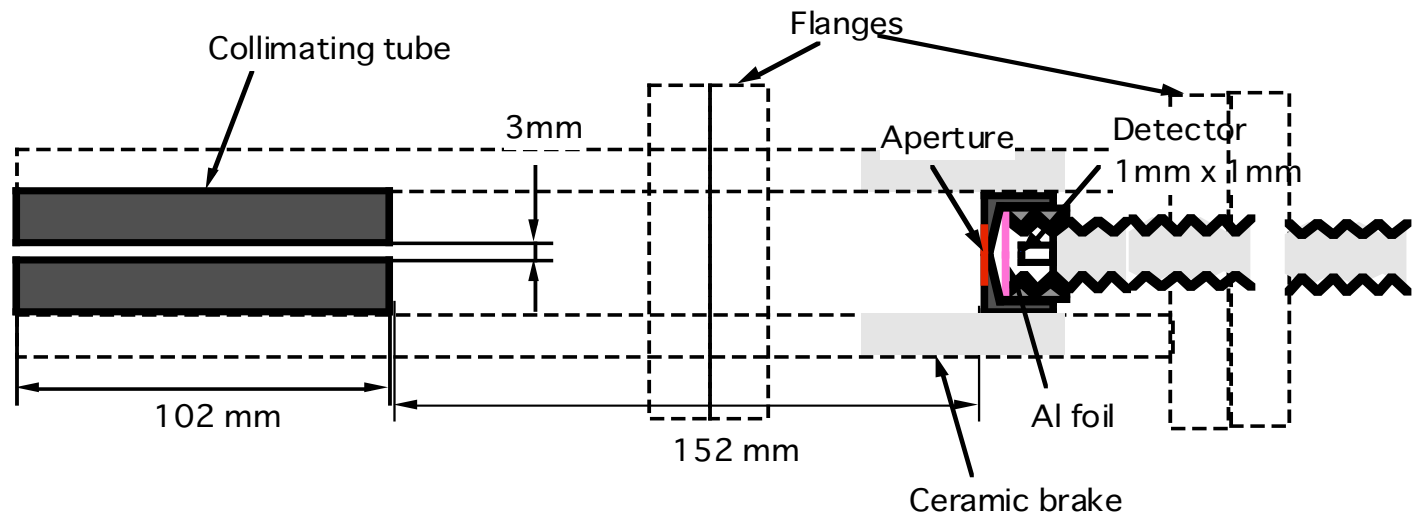

Fig. 1 Schematic view of collimating tube, aperture, $\mathrm{Al}$ foil and detector. 

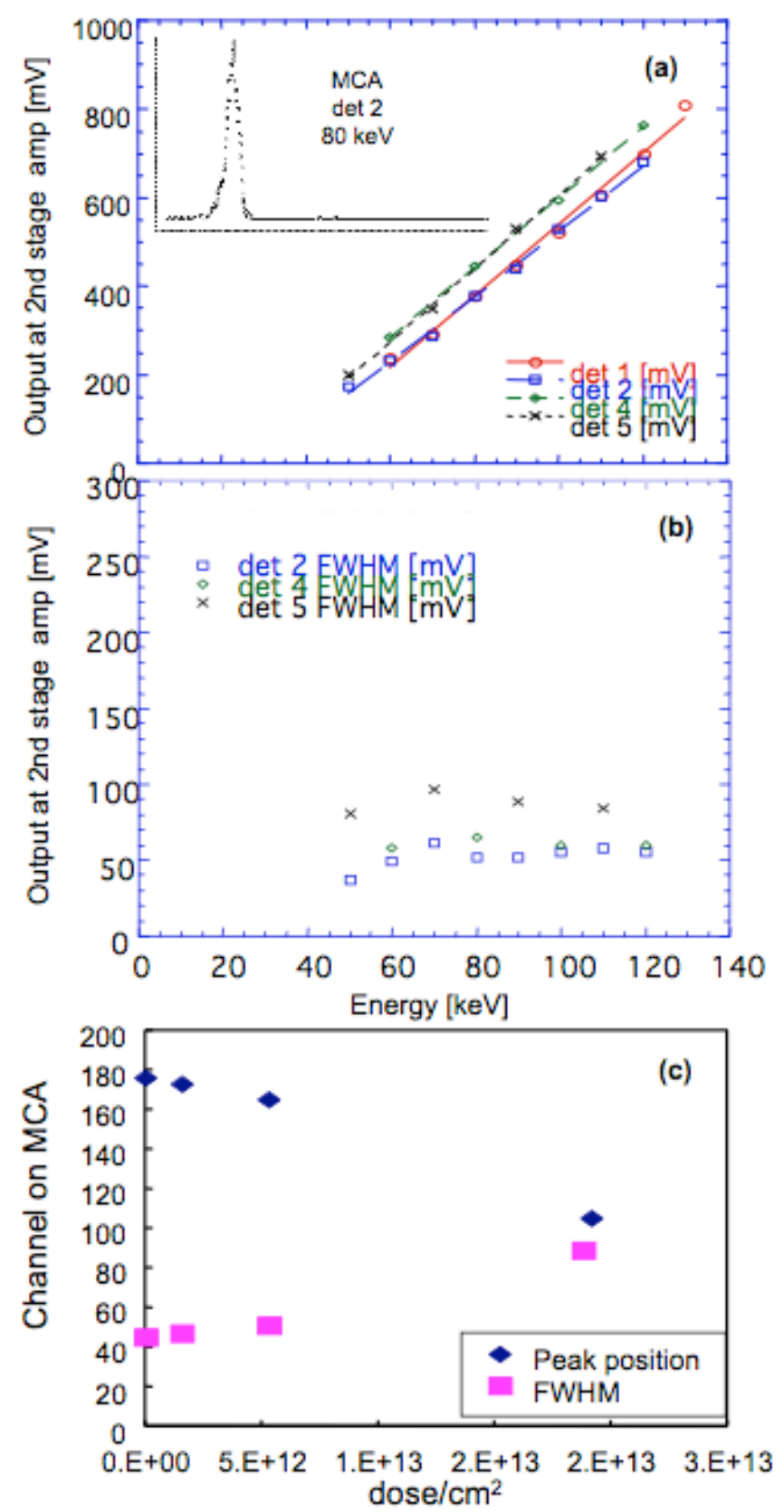

Fig. 2 (a) Peak position of spectrum versus energy of beam source. One of spectra of MCA is also shown as an example in this panel(count vs channel), (b) FWHM of spectrum versus energy of beam source, (c) degradation of detector. 


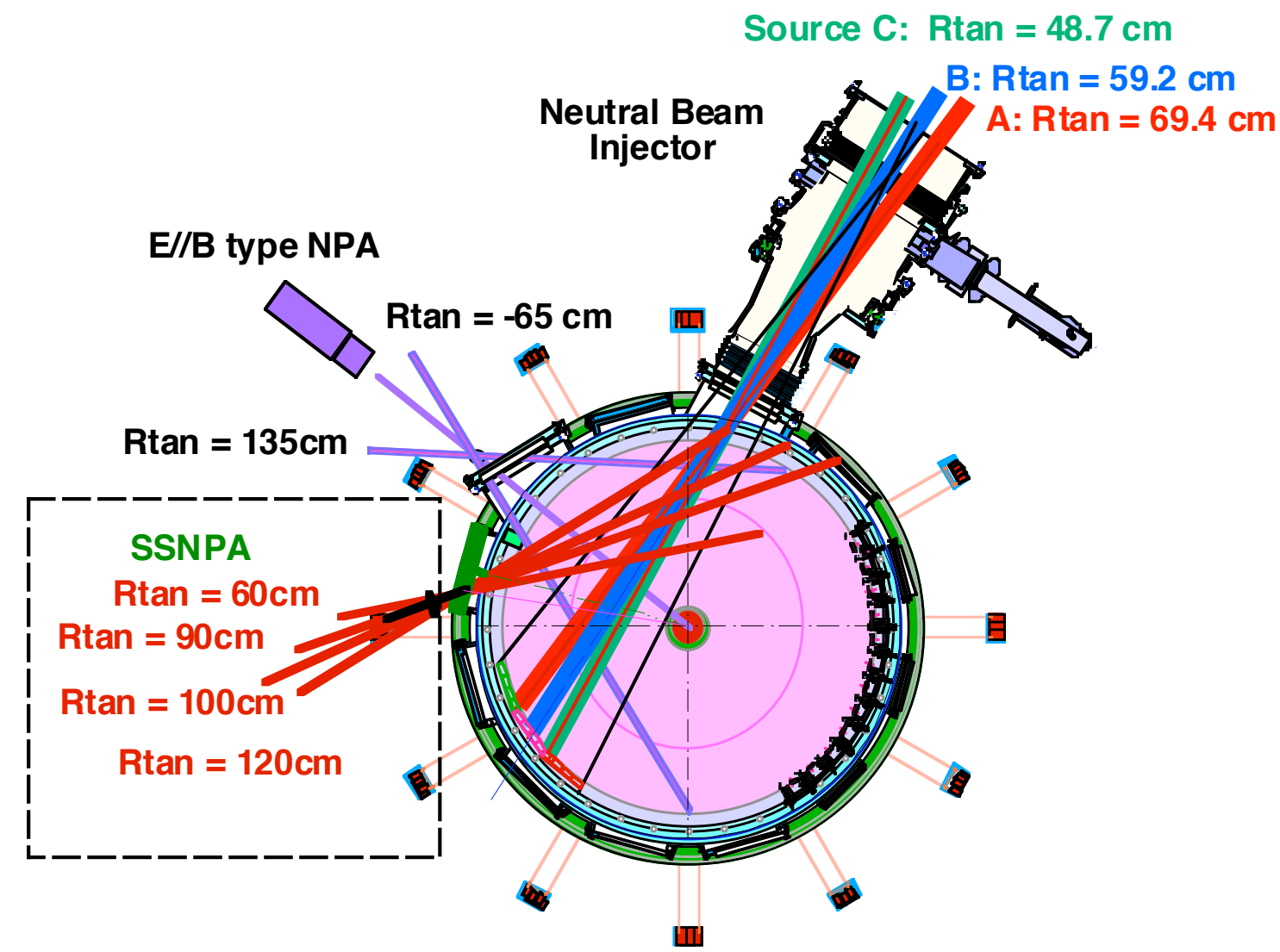

Fig. 3 Viewing chords of SSNPA array are shown with the viewing chords of E//B spectrometer and injection lines of NB on NSTX. 


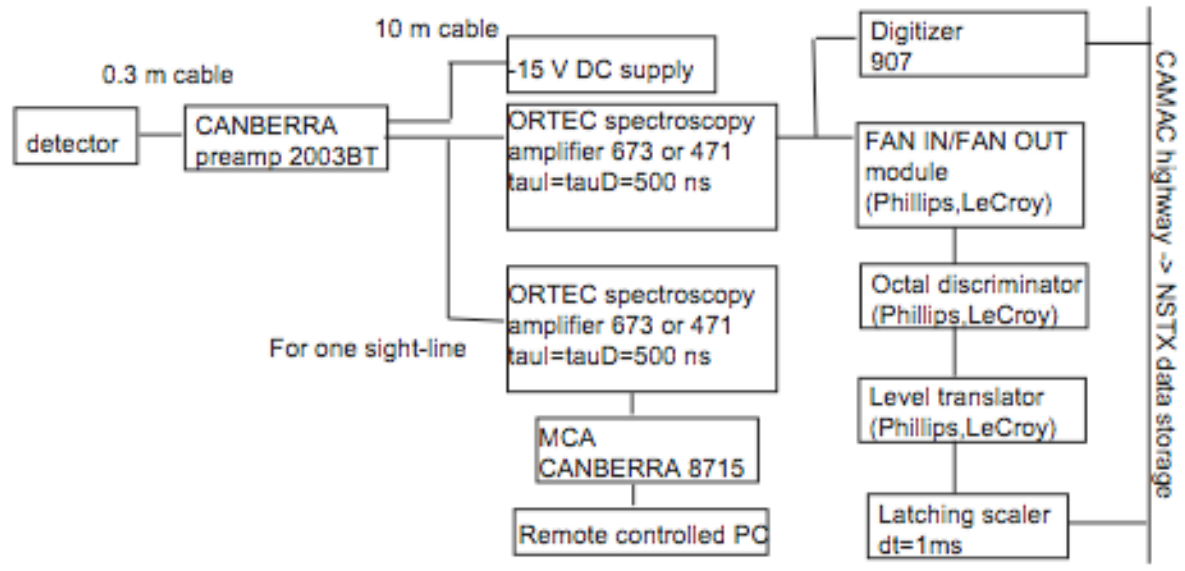

FIG. 4 Schematic diagram of electronics 


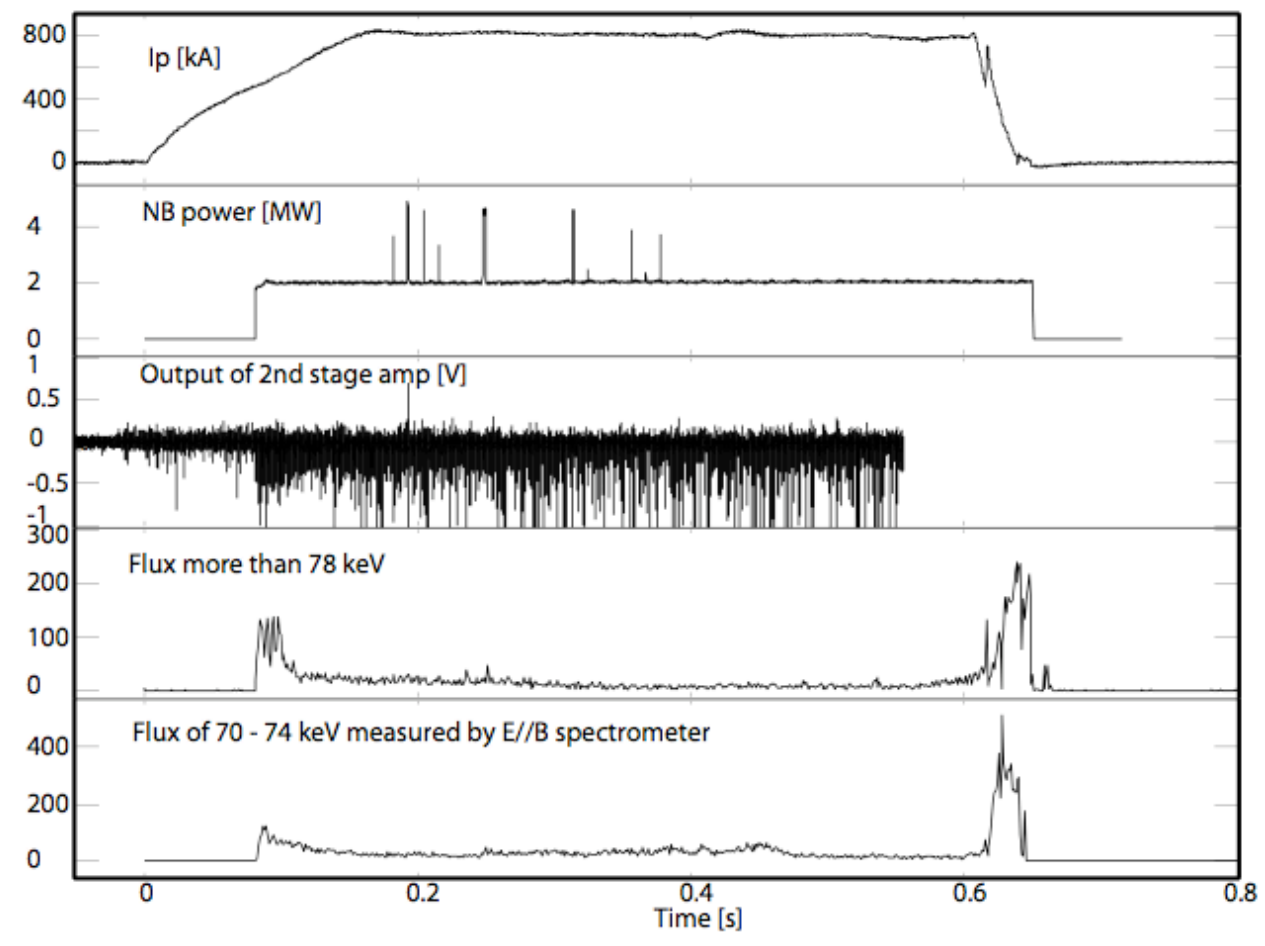

FIG. 5 Temporal evolution if Ip, NB power, counts in the scaler of sight-line \#1 of SSNPA, and in $\mathrm{E} / / \mathrm{B}$ spectrometer 


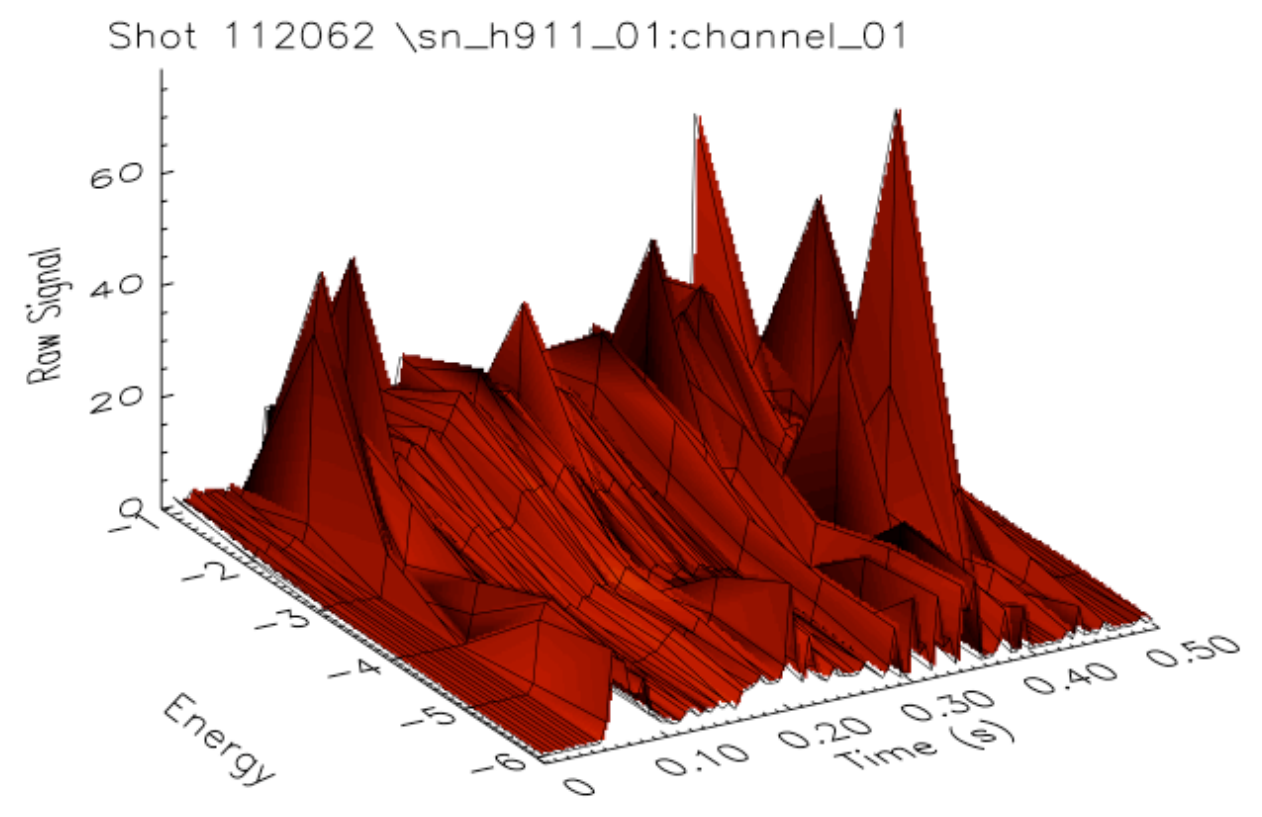

FIG. 6 Temporal evolution of energy spectrum of sight-line \#1 


\section{External Distribution}

Plasma Research Laboratory, Australian National University, Australia

Professor I.R. Jones, Flinders University, Australia

Professor João Canalle, Instituto de Fisica DEQ/IF - UERJ, Brazil

Mr. Gerson O. Ludwig, Instituto Nacional de Pesquisas, Brazil

Dr. P.H. Sakanaka, Instituto Fisica, Brazil

The Librarian, Culham Laboratory, England

Mrs. S.A. Hutchinson, JET Library, England

Professor M.N. Bussac, Ecole Polytechnique, France

Librarian, Max-Planck-Institut für Plasmaphysik, Germany

Jolan Moldvai, Reports Library, Hungarian Academy of Sciences, Central Research Institute for Physics, Hungary

Dr. P. Kaw, Institute for Plasma Research, India

Ms. P.J. Pathak, Librarian, Institute for Plasma Research, India

Ms. Clelia De Palo, Associazione EURATOM-ENEA, Italy

Dr. G. Grosso, Instituto di Fisica del Plasma, Italy

Librarian, Naka Fusion Research Establishment, JAERI, Japan

Library, Laboratory for Complex Energy Processes, Institute for Advanced Study, Kyoto University, Japan

Research Information Center, National Institute for Fusion Science, Japan

Dr. O. Mitarai, Kyushu Tokai University, Japan

Dr. Jiangang Li, Institute of Plasma Physics, Chinese Academy of Sciences, People's Republic of China

Professor Yuping Huo, School of Physical Science and Technology, People's Republic of China

Library, Academia Sinica, Institute of Plasma Physics, People's Republic of China

Librarian, Institute of Physics, Chinese Academy of Sciences, People's Republic of China

Dr. S. Mirnov, TRINITI, Troitsk, Russian Federation, Russia

Dr. V.S. Strelkov, Kurchatov Institute, Russian Federation, Russia

Professor Peter Lukac, Katedra Fyziky Plazmy MFF UK, Mlynska dolina F-2, Komenskeho Univerzita, SK-842 15 Bratislava, Slovakia

Dr. G.S. Lee, Korea Basic Science Institute, South Korea

Institute for Plasma Research, University of Maryland, USA

Librarian, Fusion Energy Division, Oak Ridge National Laboratory, USA

Librarian, Institute of Fusion Studies, University of Texas, USA

Librarian, Magnetic Fusion Program, Lawrence Livermore National Laboratory, USA

Library, General Atomics, USA

Plasma Physics Group, Fusion Energy Research Program, University of California at San Diego, USA

Plasma Physics Library, Columbia University, USA

Alkesh Punjabi, Center for Fusion Research and Training, Hampton University, USA

Dr. W.M. Stacey, Fusion Research Center, Georgia Institute of Technology, USA

Dr. John Willis, U.S. Department of Energy, Office of Fusion Energy Sciences, USA

Mr. Paul H. Wright, Indianapolis, Indiana, USA 
The Princeton Plasma Physics Laboratory is operated by Princeton University under contract with the U.S. Department of Energy.

\author{
Information Services \\ Princeton Plasma Physics Laboratory \\ P.O. Box 451 \\ Princeton, NJ 08543
}

Phone: 609-243-2750

Fax: 609-243-2751

e-mail: pppl_info@pppl.gov

Internet Address: http://www.pppl.gov 